\title{
Research on Physiological Adjustments of Textile Workers
}

\author{
Yang Ruiliang \\ School of Mechanical Engineering \\ Tianjin Polytechnic University \\ Tianjin, China \\ Yangruiliang2001@sina.com
}

\author{
Xu Zilong \\ School of Energy and Environmental Engineering \\ Zhongyuan University of Technology \\ Zhengzhou, China \\ 5914133@qq.com
}

\begin{abstract}
To investigate the physiological adjustments of textile workers exposed to high temperature environment, 10 workers with years of work experience and 12 students with rarely entering into workshop were chose to a hospital for blood test and nerve conduction velocity measurements. The blood test was to measure potassium content, sodium content, calcium content and bicarbonate content in participant's blood. Nerve conduction velocity was measured by EMG / Evoked Potentials to analyze motor nerve conduction velocity (MNCV), sensory nerve conduction velocity (SNCV). MNCV and SNCV were measured through stimulating the median nerves of right hand, in an attempt to estimate the influence of thermal experience. Different from previous literature, potassium, sodium, calcium and bicarbonate content in the blood were basically similar to the worker and student, all within normal range. Similarly, MNCV and SNCV weren't significantly different for workers and students, which mean that different thermal environment or thermal experience can't significantly affect SNCV and MNCV of subjects.
\end{abstract}

Keywords-physiological adjustments; textile workshop;blood test; motor nerve conduction velocity (MNCV), sensory nerve conduction velocity $(\mathrm{SNCV})$

\section{INTRODUCTION}

As an important livelihood industry to meet growing domestic and international market demand, the textile industry plays an irreplaceable role in the Chinese economy. According to Ref. [1], China's textile industry employs more than 20 million people. There were 38618 textile enterprises [1] in China in 2013, which means investigating the thermal condition in Chinese textile workshop is necessary.

However, the Fanger's PMV-PPD index system, recommended by ASHRAE Standard 55 [2] and ISO Standard 7730 [3] fails to predict thermal comfort for real world such as textile workshop, which is different from climate chamber. Now field study on adaptive approach includes office, resident, classroom, patient rooms, outdoor, vehicle etc. Several researchers have reviewed the literature on thermal comfort field studies [4-7].

The textile workshop is characterized by high temperature and poor thermal comfort. Temperature of textile workshop is always above $30{ }^{\circ} \mathrm{C}$ all year[1], much exceeding the optimum operative temperature $24.5^{\circ} \mathrm{C}$ by ASHRAE Standard 55 [2] and acceptable operative temperature range from 23 and $26^{\circ} \mathrm{C}$ by ISO 7730 [3]. The reason is that people naturally adapt and may also make various adjustments to themselves and their surroundings to reduce discomfort and physiological strain in warm or cold world. However, only limited documentation and information on such changes are available [8]. Chinese textile workshop often has thousands of square meters area, far exceeding the area of classroom, hospital ward, residence and other public building. Furthermore, Chinese textile industry is a typical labor-intensive industry with many workers, hot and humid environment, high noise. Most textile workers are middle-aged Chinese with operation simple, low labor intensity, single food and long work hours. These features means investigating the thermal adaptive adjustment in Chinese textile workshop is necessary.

To investigate the physiological adjustments of textile workers exposed to high temperature environment, 10 workers with years of work experience and 12 students with rarely entering into workshop were chosen as the subjects in this research. Since ASHRAE Standard 55 [1] assumes that adaptive adjustment of field studies includes salt loss, the salt contents of the blood were investigated to judge the adaptive adjustments due to subjective past thermal experiences and expectations. Liang [9] accounted that thermal environment significantly affected motor nerve conduction velocity (MNCV) and sensory nerve conduction velocity (SNCV), so MNCV and SNCV of workers and students were measured in this research..

The experiment was May 9, 2013. Subjects include 10 workers with years of work experience and 12 students with rarely entering into the workshop (see TABLE I). The selected workers with years of work experience (see TABLE II) are most typical representative of Chinese textile workers. In this study, 12 healthy college students, twelve males and eleven females, with a normal range of age, height and weight, were never entering into the textile workshop.

10 workers and 12 students were chosen to a hospital for blood test and nerve conduction velocity measurements. The blood test was to measure potassium content, sodium content, calcium content and bicarbonate content in participant's blood. Nerve conduction velocity was measured by EMG / Evoked Potentials to analyze motor nerve conduction velocity (MNCV), sensory nerve conduction velocity (SNCV). MNCV (SNCV) is a test to 
see how fast electrical signals move through the motor nerve (sensory nerve). Occasionally, MNCV and SNCV are used to evaluate diseases of nerve or muscle. Liang [9] accounted that SNCV and MNCV can change due to different thermal environment or thermal experience. In this research, MNCV and SNCV were measured through stimulating the median nerves of right hand, in an attempt to estimate the influence of thermal experience. These measurements were performed in Henan Province Hospital of Traditional Chinese Medicinal, one of the best hospitals in Henan Province.

\section{BLOOD TEST AND NERVE CONDUCTION VELOCITY}

Fig .1 and Fig .2 show test documents of blood test and nerve conduction velocity, respectively. TABLE III shows results of blood tests and nerve conduction velocity measurements. Therefore potassium, sodium, calcium and bicarbonate content in the blood were basically similar to the worker and student, all within normal range. Similarly, MNCV and SNCV weren't significantly different for workers and students, which means that different thermal environment or thermal experience can't significantly affect SNCV and MNCV of subjects. That conclusion isn't identical with Liang [9].

TABLE I. PERSONAL INFORMATION OF THE SUBJECTS

\begin{tabular}{|c|c|c|c|c|c|c|}
\hline & & $\begin{array}{l}\text { Male } \\
\text { worker }\end{array}$ & $\begin{array}{l}\text { Female } \\
\text { worker }\end{array}$ & $\begin{array}{c}\text { Male } \\
\text { student }\end{array}$ & $\begin{array}{l}\text { Female } \\
\text { student }\end{array}$ & Total \\
\hline \multicolumn{2}{|c|}{ Sample size } & 5 & 5 & 6 & 6 & 22 \\
\hline \multirow{3}{*}{ Age (years) } & Avg. & 45.2 & 42.8 & 24.2 & 23.0 & 36.6 \\
\hline & Min. & 24 & 24 & 23 & 22 & 22 \\
\hline & Max. & 55 & 51 & 27 & 26 & 55 \\
\hline \multirow{3}{*}{ Height (cm) } & Avg. & 169.7 & 159.4 & 175.3 & 160.6 & 165.5 \\
\hline & Min. & 162 & 150 & 170 & 153 & 150 \\
\hline & Max. & 178 & 165 & 185 & 168 & 185 \\
\hline \multirow{3}{*}{ Weight (kg) } & Avg. & 70.7 & 58.6 & 72.7 & 49.2 & 63.0 \\
\hline & Min. & 60 & 48 & 63 & 43 & 43 \\
\hline & Max. & 82 & 74 & 90 & 54 & 90 \\
\hline \multirow{5}{*}{$\operatorname{BMI}^{*}\left(\mathrm{~kg} / \mathrm{m}^{2}\right)$} & Avg. & 24.56 & 23.10 & 23.66 & 19.09 & 22.92 \\
\hline & Min. & 20.83 & 18.75 & 20.90 & 16.90 & 16.89 \\
\hline & Max. & 29.02 & 29.41 & 27.78 & 20.83 & 29.41 \\
\hline & \multirow{2}{*}{\multicolumn{6}{|c|}{ 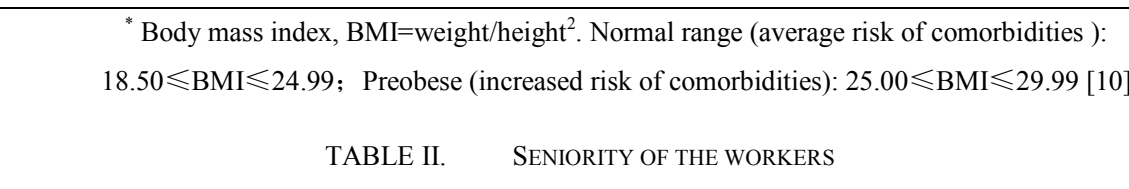 }} \\
\hline & & & & & & \\
\hline Sample & \multicolumn{3}{|c|}{ Male worker } & \multicolumn{3}{|c|}{ Female worker } \\
\hline \multicolumn{2}{|l|}{ Seniority } & $10 \sim 30$ & $>30$ & & $10 \sim 30$ & $>30$ \\
\hline \multicolumn{2}{|l|}{ Number } & 2 & 3 & & 3 & 2 \\
\hline \multicolumn{2}{|l|}{ Total } & \multicolumn{5}{|c|}{10} \\
\hline
\end{tabular}




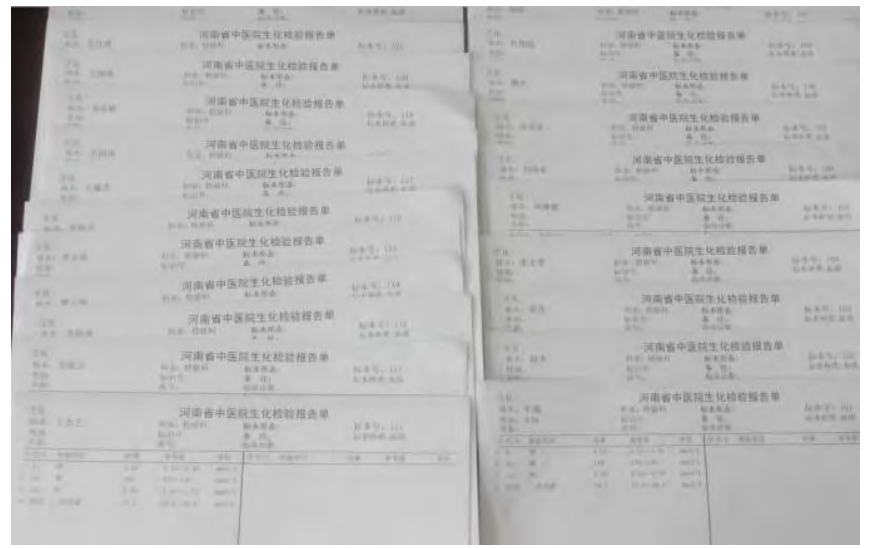

Figure 1. Test documents of blood test

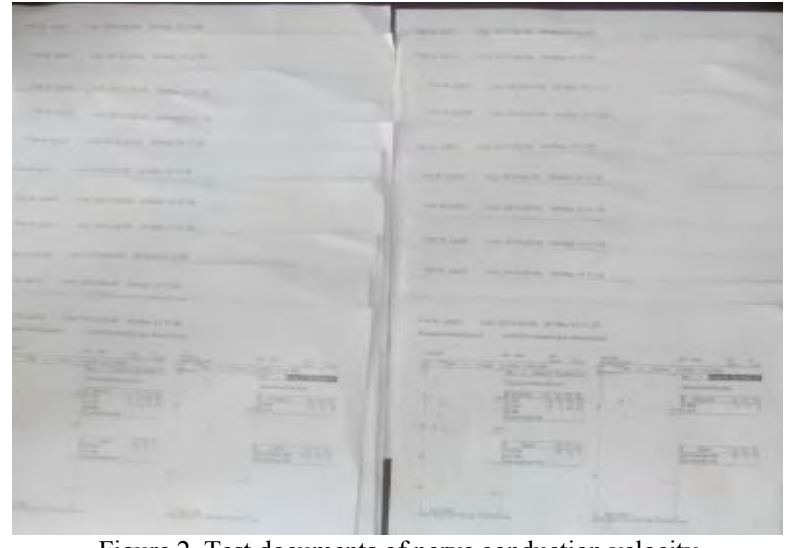

Figure 2. Test documents of nerve conduction velocity

TABLE III. RESULTS OF BLOOD TEST AND NERVE CONDUCTION VELOCITY MEASUREMENTS

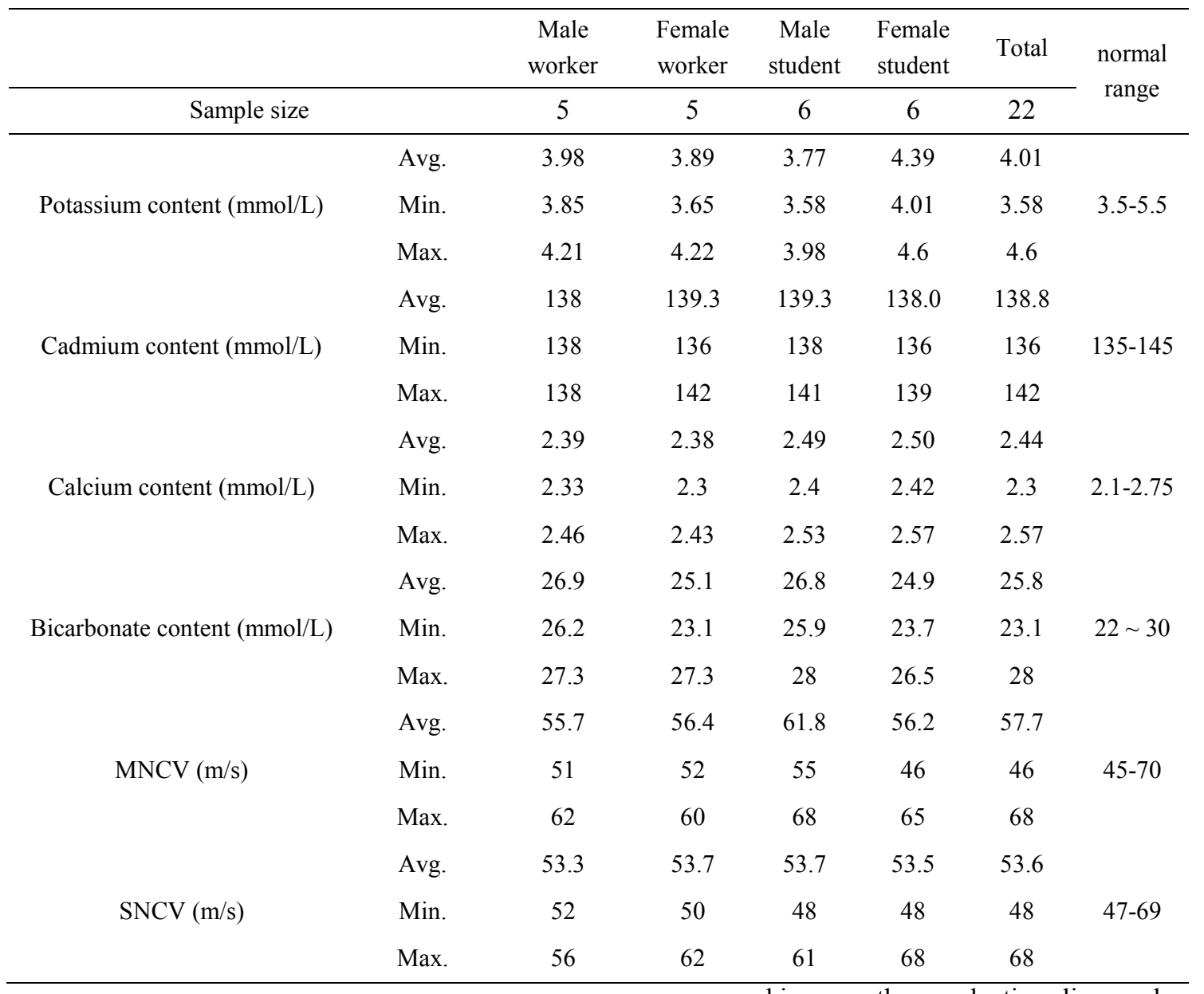

\section{DISCUSSION}

Human response conditions in the textile workshop may be influenced by a range of complex factors that are not accounted for in the heat balance models. The literature [4] distinguishes three modes of adaptation: behavioral adjustment, physiological acclimatization and psychological habituation.

Behavioral adjustment includes personal adjustment, technological, adjustment and cultural adjustment [4]. For textile workers, they can't randomly walking around, working on the production line and wearing working clothes. Workshop air conditioning is controlled by specialized air conditioning workers, and textile workers can't turn on/off workshop air conditioning or change the air volume. Furthermore, since the textile workshop doesn't have exterior windows (workshop is next to attached house with exterior windows, but workshop hasn't exterior windows), textile workers can't open /close windows to modify their thermal comfort. The corporation distributes the work in three shifts, and each worker must be one morning shift, one late shift and one night shift in three days, so workers could not adjust the scheduling schedule to achieve a more comfortable thermal 
environment. Because worker's meals are all simple food made by just one canteen, worker basically can't make their own adjustments. So in the type of behavioral adjustment defined by Ref. [4], workers can only drink hot water to control their own sweat, slightly changing their thermal situation. Obviously, the effect of this type behavioral adjustment is very limited.

Physiological acclimatization can be subcategorized as genetic adaptation and acclimation. Genetic adaptation has become part of the genetic heritage, developing at time scales beyond that of an individual's lifetime. According to the surveys, the worker's parents haven't the experience in the textile industry. Work in textile workshop is monotonous and lifeless, with poor working environment, lower wages and benefits, so the majority of investigated workers are reluctant to be engaged in this work. Because of well-trained and inertia, they continue to be engaged in this work, but they would not like their children do this job. That is, the problem of genetic adaptation due to long-term thermal environment doesn't exist for textile workers. However, many workers had a long-time work experience in the textile workshop, which may affect their nerves and the physiological thermoregulation. In the surveys, only parts of workers' bodies became wet due to sweat, while whole students' bodies became wet, suggesting that workers can more adapt to the textile workshop than students can. But not the same as expected, blood salt content in the blood, MNCV, SNCV are basically the same for workers and students in the hospital measurement, which indicates that high temperature and humidity of textile workshop don't affect worker's physiological parameters such as blood salt content in the blood, MNCV, SNCV.

Psychological habituation is described in psychophysics as repeated or chronic exposure to an environmental stressor leading to a diminution of the evoked sensation's intensity. In the surveys, the worker basically complained their wages and benefits instead of the thermal environment, while the majority of students keep complaining about the workshop thermal environment and sound environment. This fact indicates that compared to the student, the worker with long-hour experience in the textile workshop has a low expectations for the workshop thermal environment, so the worker can more adapt workshop thermal environment. This conclusion can be tested in literature [11], with the PMV overestimating the AMV of workers and underestimating the AMV of students.

\section{CONCLUSION}

The physiological adjustments of textile workers exposed to high temperature environment were researched in this paper. 10 workers with years of work experience and 12 students with rarely entering into workshop were chose to a hospital for blood test and nerve conduction velocity measurements.

ASHRAE Standard 55 assumes that adaptive adjustment of field studies includes salt loss, the salt contents of the blood were investigated to judge the adaptive adjustments due to subjective past thermal experiences and expectations, but blood test in this research shows that salt contents of the blood were basically similar to the worker and student, all within normal range. Liang [8] accounted that thermal environment significantly affected motor nerve conduction velocity (MNCV) and sensory nerve conduction velocity (SNCV), but nerve conduction velocity measurements in this research shows $\mathrm{MNCV}$ and SNCV weren't significantly different for workers and students, which mean that different thermal environment or thermal experience can't significantly affect SNCV and MNCV of subjects.

\section{ACKNOWLEDGMENT}

This research was supported by the NSFC (the Natural Science Foundation of China) No. 51208527 and Funding Scheme for Young Teachers of Higher School in Henan Province (2012GGJS -124).

\section{REFERENCES}

[1] China textile industry association. 2013/2014 China textile industry development report. Chinese textile Press; 2014 [in Chinese].

[2] ANSI/ASHRAE Standard 55-2013. Thermal environment conditions for human occupancy. American Society of Heating, Refrigerating and Air-Conditioning Engineer, Inc; 2013.

[3] ISO7730. Ergonomics of the thermal environment- Analytical determination and interpretation of thermal comfort using calculation of the PMV and PPD indices and local thermal comfort criteria. International Organization for Standardization; 2005 [Switzerland].

[4] Brager GS, de Dear RJ. Thermal adaptation in the built environment: A literature review. Energy and Building 1998; 27: 83 - 96.

[5] Liu Y Haiyan Y, Joseph CL. Thermal comfort and building energy consumption implications -A review. Applied Energy 2014; 115 : 164-173.

[6] Djongyang N, Tchinda R, Njomo D. Thermal comfort: A review paper. Renewable and Sustainable Energy Reviews 2010; 14: 2626-2640.

[7] Humphreys, MA. Field studies and climate chamber experiments in thermal comfort research. Thermal Comfort: Past Present and Future. Garston, UK: Building Research Esablishment, 1994.

[8] ASHRE Handbook-Fundamental. American Society of Heating, Refrigerating and Air-Conditioning Engineer, Inc. 2009.

[9] Liang C. Experimental study on indoor thermal environment of human physiology and thermal comfort. Chongqing University, Master's thesis, 2006.

[10] World Health Organization. Obesity: Preventing and Managing the Global Epidemic. WHO Technical Report Series 894. Geneva: World Health Organization, 2000 [Switzerland].

[11] YANG Ruiliang,ZHOU Yide, XU Zilong. Research on thermal comfort in cotton textile workshop. Journal of textile research, 2014, accepted. 